\title{
High Temperature Materials Interim Data Qualification Report
}

\author{
Nancy Lybeck
}

The INL is a

U.S. Department of Energy National Laboratory

operated by

Battelle Energy Alliance

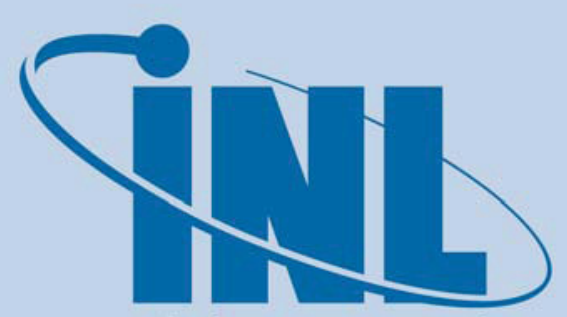

Idaho National Laboratory
August 2010

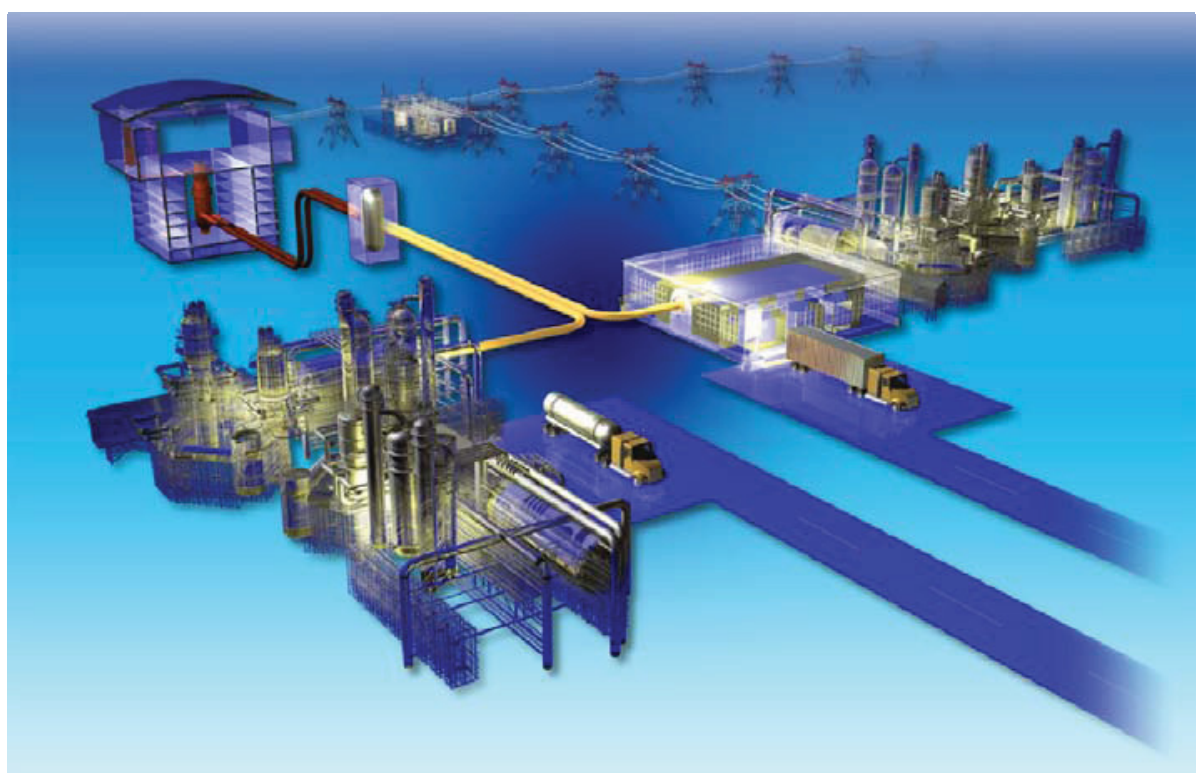




\section{DISCLAIMER}

This information was prepared as an account of work sponsored by an agency of the U.S. Government. Neither the U.S. Government nor any agency thereof, nor any of their employees, makes any warranty, expressed or implied, or assumes any legal liability or responsibility for the accuracy, completeness, or usefulness, of any information, apparatus, product, or process disclosed, or represents that its use would not infringe privately owned rights. References herein to any specific commercial product, process, or service by trade name, trade mark, manufacturer, or otherwise, does not necessarily constitute or imply its endorsement, recommendation, or favoring by the U.S. Government or any agency thereof. The views and opinions of authors expressed herein do not necessarily state or reflect those of the U.S. Government or any agency thereof. 


\title{
High Temperature Materials Interim Data Qualification Report
}

\author{
Nancy Lybeck
}

August 2010

Idaho National Laboratory

Next Generation Nuclear Plant Project

Idaho Falls, Idaho 83415

Prepared for the

U.S. Department of Energy

Office of Nuclear Energy

Under DOE Idaho Operations Office

Contract DE-AC07-05ID14517 

Next Generation Nuclear Plant Project

\section{High Temperature Materials Interim Data Qualification Report}

INL/EXT-10-19563

August 2010
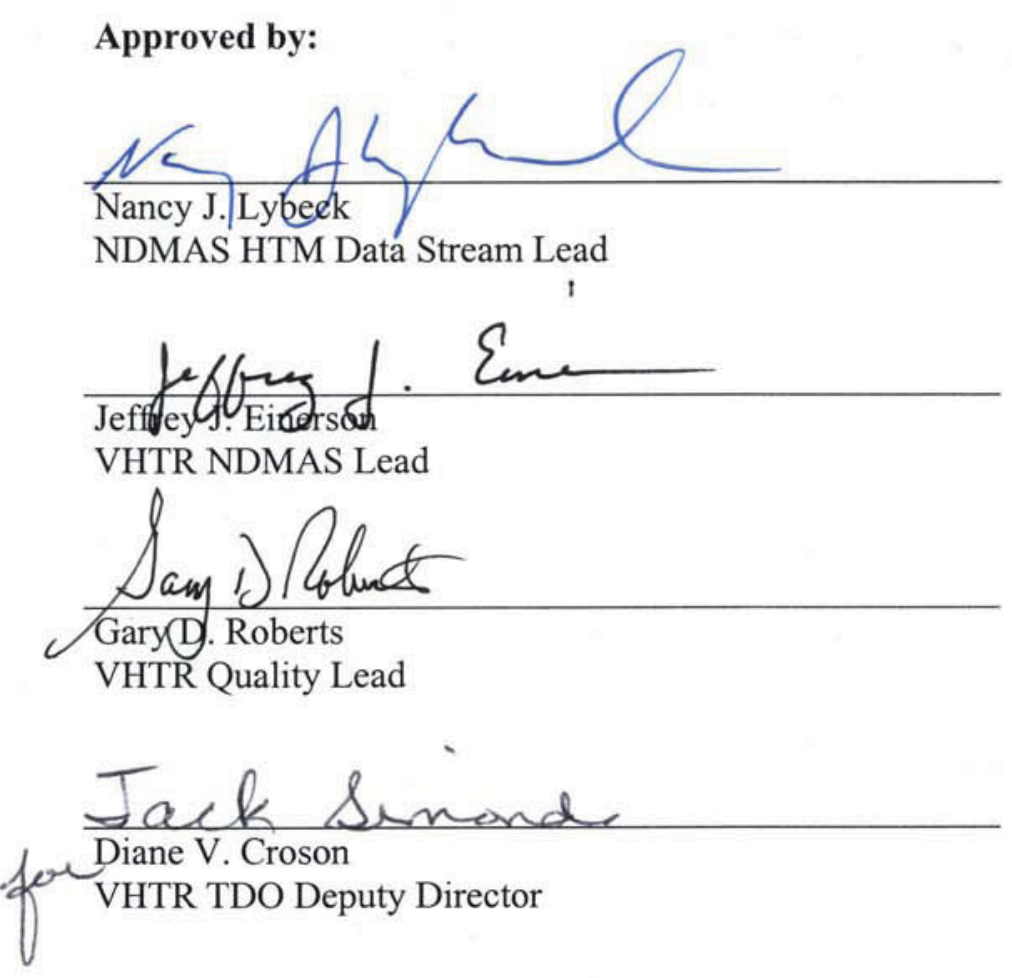



\section{ABSTRACT}

Projects for the very high temperature reactor (VHTR) Technology Development Office provide data in support of Nuclear Regulatory Commission licensing of the VHTR. Fuel and materials to be used in the reactor are tested and characterized to quantify performance in high temperature and high fluence environments. The VHTR program has established the Next Generation Nuclear Plant (NGNP) Data Management and Analysis System (NDMAS) to ensure that VHTR data are qualified for use, stored in a readily accessible electronic form, and analyzed to extract useful results.

This document focuses on the first NDMAS objective. It describes the High Temperature Materials characterization data stream, the processing of these data within NDMAS, and reports the interim fiscal year (FY) 2010 qualification status of the data. Data qualification activities within NDMAS for specific types of data are determined by the data qualification category assigned by the data generator. The High Temperature Materials data are being collected under the Nuclear Quality Assurance (NQA)-1 guidelines and will be qualified data. For NQA-1 qualified data, the qualification activities include: (1) capture testing to confirm that the data stored within NDMAS are identical to the raw data supplied, (2) accuracy testing to confirm that the data are an accurate representation of the system or object being measured, and (3) documenting that the data were collected under an NQA-1 or equivalent Quality Assurance program.

Currently, data from two test series within the High Temperature Materials data stream have been entered into the NDMAS vault:

1. Tensile Tests for $\mathrm{S}_{\mathrm{m}}$ (i.e., Allowable Stress) Confirmatory Testing 1,403,994 records have been inserted into the NDMAS database. Capture testing is in process.

2. Creep-Fatigue Testing to Support Determination of Creep-Fatigue Interaction Diagram - 918,854 records have been processed and inserted into the NDMAS database. Capture testing is in process. 


\section{CONTENTS}

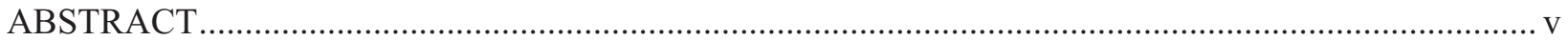

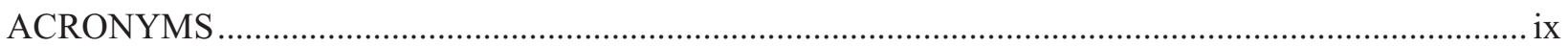

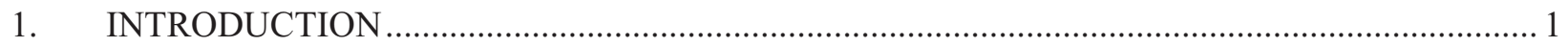

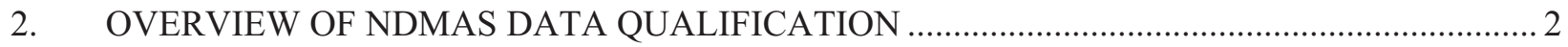

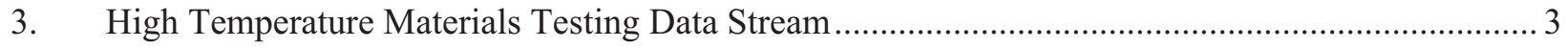

3.1 HTM Data Processing within NDMAS _........................................................................... 3

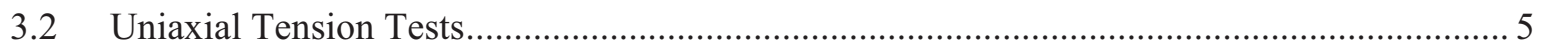

3.2.1 A-1: Tensile Tests for $\mathrm{S}_{\mathrm{m}}$ Confirmatory Testing.................................................. 7

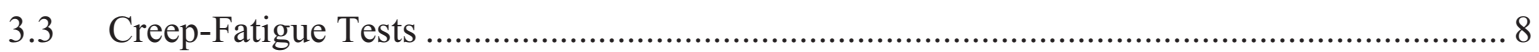

3.3.1 A-20: Creep-fatigue Tests to Support Determination of Creep-Fatigue

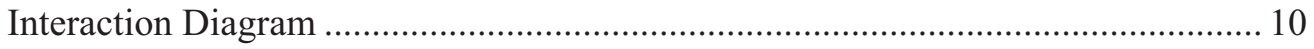

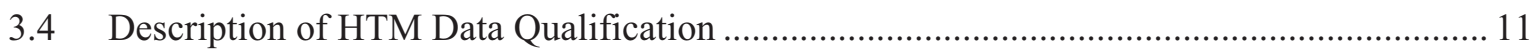

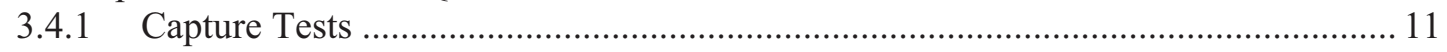

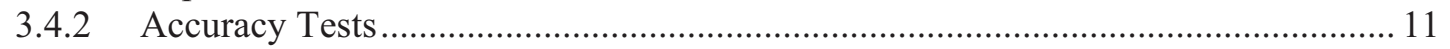

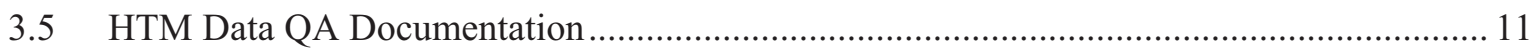

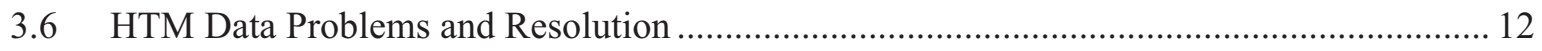

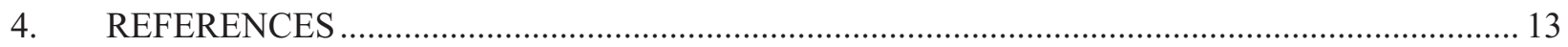

\section{FIGURES}

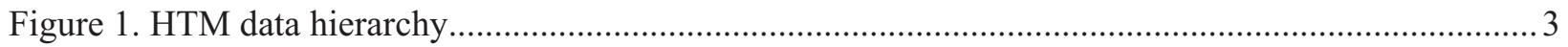

\section{TABLES}

Table 1. High temperature materials test series (Wright 2008) .......................................................... 4

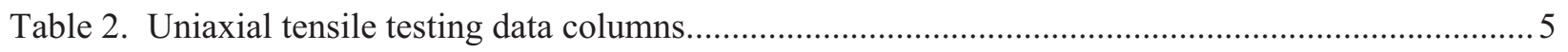

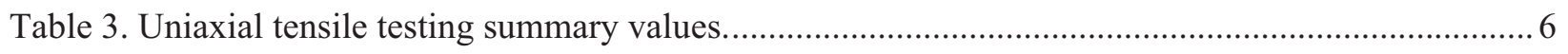

Table 4. Parameters and classification for high temperature materials characterization - uniaxial

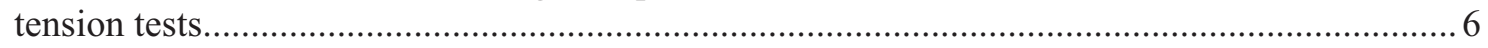

Table 5. Enterprise Guide Projects for processing A-1 data ................................................................ 7

Table 6. Data columns for original creep-fatigue procedure ............................................................... 8

Table 7. Data columns for revised creep-fatigue procedure. ............................................................. 9

Table 8. Parameters and classification for high temperature materials characterization-creep

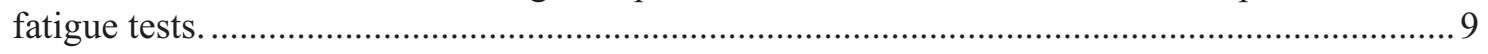

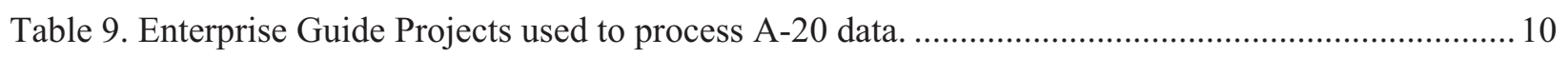

Table 10. Qualification status of the HTM data currently entered in the NDMAS database. .................... 12 


\section{ACRONYMS}

ASME American Society of Mechanical Engineers

ASTM American Society for Testing and Materials International

ECAR Engineering Calculations and Analysis Report

EDF Engineering Design File

FY fiscal year

HTM High Temperature Materials

INL Idaho National Laboratory

NDMAS NGNP Data Management and Analysis System

NGNP Next Generation Nuclear Plant

NQA Nuclear Quality Assurance

QA Quality Assurance

QAPP Quality Assurance Program Plan

RT room temperature

SQL Structured Query Language

TDO Technology Development Office

VHTR Very High Temperature Gas-Cooled Reactor 


\section{High Temperature Materials Interim Data Qualification Report}

\section{INTRODUCTION}

This report provides the interim fiscal year (FY) 2010 status of High Temperature Materials (HTM) data qualification as performed by the Next Generation Nuclear Plant (NGNP) Data Management and Analysis System (NDMAS). The HTM data experiments are a series of laboratory characterizations that address the code case development and licensing issues identified for Alloy 617 and Alloy $800 \mathrm{H}$ in support of the design and licensing of a very high temperature reactor (VHTR). HTM testing is expected to continue for several years.

This report gives the current data qualification status of the HTM data sets that have been processed by NDMAS. 


\section{OVERVIEW OF NDMAS DATA QUALIFICATION}

NDMAS was developed to provide a single controlled repository for all NGNP data, documentation of and assistance in data qualification, advanced data analysis, and Web access to the data. A detailed discussion of the NDMAS structure and the data qualification requirements performed within NDMAS is given in the VHTR Program Data Management and Analysis Plan (Hull et al., 2010).

Data qualification is the act of reviewing, inspecting, testing, checking, or otherwise verifying and documenting whether data conform to specified requirements, as defined by the data users and the performing organization. Depending upon the data stream, data qualification may be performed by one or more entities, including independent technical reviewers, Quality Assurance (QA), data review committees, and testing performed within NDMAS. This process also considers whether the data were collected within an American Society of Mechanical Engineers (ASME) Nuclear Quality Assurance Nuclear Quality Assurance (NQA)-1 or equivalent approved QA program. Data qualification within NDMAS is documented as one of three qualification states:

1. Qualified. Data collected within an NQA-1 or equivalent QA program are independently verified to meet the requirements for a specific end use as defined in a data collection plan. Any nonconformance is concluded to not affect the usability of the data.

2. Trend. Data collected within an NQA-1 or equivalent approved QA program where the qualification process identifies minor flaws or gaps in meeting data requirements, although the data are still considered useful by the program. Trend data captured into NDMAS are tested to verify the capture and may be subjected to some accuracy testing.

3. Failed. The data do not meet specified requirements. This may be for a number of reasons, including inadequate data collection methods, instrument failure or drift, or poor accuracy.

There may also be data types collected within the program that are only for information. These data are not qualified because specific data qualification requirements cannot be defined or independent verification is not needed or desired. These data are processed by NDMAS for display on the Web and are then archived or stored in their native file format for possible future use.

Data processing consists of capture, verification of capture, and optionally, testing for anomalies or accuracy. The capture process includes reading the raw data files, converting date/time values to Mountain Standard Time, changing measurement units to standard units, removing duplicate values, and creating $\mathrm{SAS}^{\circledR}$ datasets. Capture testing includes manual and automated checks to verify there are no obvious data processing errors in the source files (e.g., date/time chronology checks) and that the data stored within NDMAS are identical (or equivalent if, for example, the units have been changed) to the source data provided to NDMAS.

Optionally, tests are performed to identify anomalies. Anomalies identified by these tests are then examined with input from the technical leads and resolved to determine whether the anomalies represent instrument failures or other errors that disqualify ("fail") the data or values that are unusual but reliable. The outcome of anomaly testing is tracked using an internal NDMAS accuracy pass/fail flag. Data qualification, described below, is tracked separately.

The primary component of data qualification is independent verification that data collected within an NQA-1 compliant QA program (or equivalent) meet requirements for the intended use identified in plans. For the HTM data stream, approved Engineering Calculations and Analysis Reports (ECARs) or external reports will be used to document that data collection requirements were met. Within the VHTR program, the NQA-1 data collection requirements are implemented through the Very-High-Temperature GasCooled Reactor Technology Development Office Quality Assurance Program Plan (VHTR Technology 
Development Office TDO QAPP) Roberts et al. 2009. NDMAS stores references to the reports that document the conformance of the specific data collection activities to the NQA-1 requirements, and tracks the qualification status of each stored value using a data qualification flag. The relevant documents that specify NQA-1 requirements and conformance for each type of testing within the HTM data stream are given in Section 3.5 of this report.

\section{High Temperature Materials Testing Data Stream}

Today's high temperature alloys and associated ASME codes for reactor applications are approved up to $750^{\circ} \mathrm{C}$. However, some primary system components, such as the intermediate heat exchanger for the VHTR, will require the use of materials that can withstand higher temperatures. The thermal, environmental, and service life conditions of the NGNP will make selection and qualification of some high temperature materials a significant challenge.

A large matrix of testing has been developed (Wright, 2008) to support the design and licensing of a VHTR. These laboratory characterization experiments will be conducted to address the code case development and licensing issues identified for Alloy 617 and Alloy $800 \mathrm{H}$. Guidelines for approving materials for high-temperature applications ask for tensile strength, yield strength, reduction of area, and elongation at $50^{\circ} \mathrm{C}$-increments from room temperature to $50^{\circ} \mathrm{C}$ above the maximum intended use temperature and over a range of strain rates. Weld strength rupture factors will be determined for two welding processes as a function of time and temperature. Other properties to be measured at elevated temperatures (up to $1,000^{\circ} \mathrm{C}$ ) include elastic modulus, Poisson's Ratio, linear thermal expansion, thermal conductivity, thermal diffusivity, and density. Additional laboratory investigations will characterize weld creep-fatigue, effect of helium impurities, and aging effects on fracture toughness. Test durations vary from minutes to years. Each test series, listed in Table 1, consists of multiple experiments. In this document, the name of the test series will be used for identification purposes (e.g., A-1).

All data are being collected under NQA-1 guidelines. There are multiple sets of experiments ongoing at this time. To date, data from two test series have been pushed to the NDMAS data vault: A-1 and A-20.

\subsection{HTM Data Processing within NDMAS}

Prior to capturing the data in NDMAS, a hierarchical data structure based on experiments was created to make the data easier to process and analyze. In particular, the HTM data need to be easily queried by experiment and by alloy. Components in NDMAS are related to each other by an assembly tree. The assembly tree for HTM is a simple hierarchical structure, seen in Figure 1. The sample name should include the alloy to enable the ability to query by alloy.

Data processing and storage within NDMAS occurs via the following process. Raw data files covering one test series (e.g., A-1) are periodically placed in folders on the FSEROB1 server, creating a data package. A batch file is run to copy the new data files to the NDMAS data archive and to update an NDMAS-maintained list of files waiting processing. The data archive is part of a subversion repository, which tracks any changes made to the files after the original data transfer.

There is no fixed data transfer schedule for the HTM data stream. The timing of the transfer is left to the discretion of the data generators.

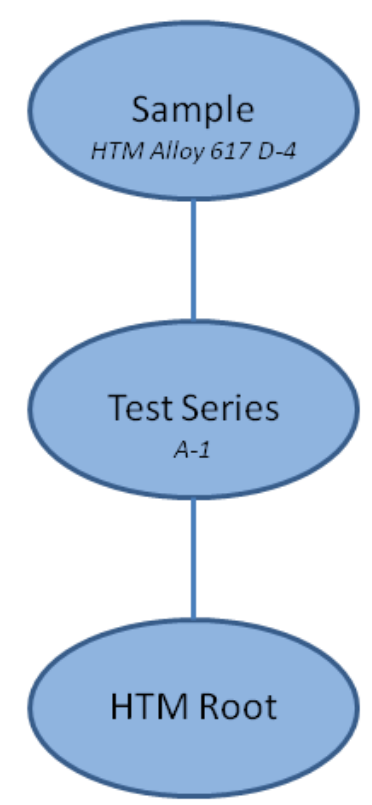

Figure 1. HTM data hierarchy. 
The type and amount of incoming data varies for each test series. Because it is anticipated that similar test series listed in Table 1will result in similar output data, more specific information is provided in the following sections based on the type of testing. Although there are multiple types of tests scheduled to be performed, only uniaxial tension tests (A-1) and creep-fatigue tests (A-20) are currently represented in the vault.

Table 1. High temperature materials test series (Wright 2008).

\begin{tabular}{|c|c|}
\hline $\begin{array}{l}\text { Test } \\
\text { Series }\end{array}$ & Description \\
\hline A-1 & Tensile Tests for $\mathrm{S}_{\mathrm{m}}$ Confirmatory Testing \\
\hline A-2 & Weld Strength Rupture Factor Determination Test \\
\hline A-3 & Creep-Fatigue Tests for Alloy 617 Welds \\
\hline A-4 & Aging Effects on Fracture Toughness of Alloy 617 Wrought Metal \\
\hline A-5 & Tensile Tests to Determine Strain Rate Sensitivity in Support of Unified Constitutive Model \\
\hline A-6 & Torsion Tests for Validating Von Mises Criterion to Support Unified Constitutive Model \\
\hline A-7 & Stress Dip Tests in Support of Unified Constitutive Model \\
\hline A-8 & Short-term (Days) Creep Tests to Support Unified Constitutive Model \\
\hline A-9 & Uniaxial Ratcheting Tests to Support Unified Constitutive Model \\
\hline A-10 & Torsional Cycling with Constant Axial Strain to Support Unified Constitutive Model \\
\hline A-11 & Loading-Unloading-Creep Sequence to Support Unified Constitutive Model \\
\hline A-12 & Thermomechanical Cycling to Support Unified Constitutive Model \\
\hline A-13(a) & Creep Curves to Qualify Unified Constitutive Model \\
\hline A-13(b) & Stress Relaxation Tests for Qualifying Unified Constitutive Model \\
\hline A-14 & Uniaxial Tests on Thermally Aged Alloy 617 to Support Unified Constitutive Model \\
\hline A-15 & Tube Burst Tests for Alloy 617 and Alloy $800 \mathrm{H}$ \\
\hline A-16 & Creep-Fatigue Tests for SMT Specimens \\
\hline A-17 & Long Term Alloy 617 Creep Rupture Tests for Qualification \\
\hline A-18 & Thermal Aging Tests for Strength Reduction Factors \\
\hline A-19 & Fatigue Tests to Support Design Curve Development in Alloy 617 Code Case \\
\hline A-20 & Creep-fatigue Test Matrix to Support Determination of Creep-Fatigue Interaction Diagram \\
\hline A-21 & Tests to Determine "C" Factor in Multiaxial Creep Rupture Strength Criterion for Alloy 617 \\
\hline A-22 & Interrupted Creep Tests \\
\hline A-23 & Creep-Fatigue Saturation with Hold Time \\
\hline A-24 & Exploration of Creep Mechanisms for Alloy 617 \\
\hline A-25 & Determination of Grain Size Rupture Factors for Alloy 617 \\
\hline A-26 & Tensile Tests Supporting Unified Constitutive Model for Alloy $800 \mathrm{H}$ \\
\hline A-27 & Weld Strength Rupture Factor for Alloy $800 \mathrm{H}$ Weldments \\
\hline A-28 & Strain Rate Effect on Yield and Tensile Strength for Alloy $800 \mathrm{H}$ \\
\hline A-29 & Exploration of Creep Mechanisms of Alloy $800 \mathrm{H}$ \\
\hline A-30 & $\begin{array}{l}\text { Qualification of Yield and Tensile Strength Reduction Factors for Alloy } 800 \mathrm{H} \text { Due to } \\
\text { Thermal Aging }\end{array}$ \\
\hline A-31 & Tests to Validate "C" Factor in Multiaxial Creep Rupture Strength Criterion for Alloy $800 \mathrm{H}$ \\
\hline
\end{tabular}




\subsection{Uniaxial Tension Tests}

Several uniaxial tension test series are listed in Table 1, including A-1, A-5, A-14, A-26, A-28, and A-30. Although each test series has a different goal, the tests will be performed using the same test rigs and will produce similar data sets.

The tensile testing procedure (Chapman, et al., 2009) outlines the procedure for determining the mechanical tensile properties of nominally homogeneous materials, either at room temperature or at elevated temperature. The test specimens are assumed to conform to the American Society for Testing and Materials International (ASTM) Standard Test Methods E8 or E21. Relevant ASTM standards are:

- ASTM Standard E21-09, "Standard Test Methods for Elevated Temperature Tension Tests of Metallic Materials"

- ASTM Standard E8/E8M-08, "Standard Test Methods for Tension Testing of Metallic Materials"

- ASTM Standard E4-09, "Standard Practice for Force Verification of Testing Machines"

- $\quad$ ASTM Standard E83-06, "Standard Practice for Verification and Classification of Extensometer System"

- ASTM Standard E220-07a, "Standard Test Method for Calibration of Thermocouples by Comparison Techniques."

The tensile data for each experiment consists of a single Excel file. The name of the file contains a variety of information about the experiment, including the sample name, alloy, and baseline temperature. This information is not consistently contained within the file itself. The sample name is always included as part of the header information, but the other information is not. Typical file names include Alloy.617.QA.151053-D-4.700C.Charts.xls and 800H.QA.HTM10-001.H4.RT.xls (where RT stands for room temperature).

Each spreadsheet contains one or more worksheets (tabs) based on the amount of data collected. The data in each column is listed in Table 2.

Table 2. Uniaxial tensile testing data columns.

\begin{tabular}{|ll|}
\hline Col. & \multicolumn{1}{|c|}{ Value } \\
\hline A & Time $(\mathrm{sec})$ \\
B & Crosshead Position $(\mathrm{mm})$ \\
C & Force $(\mathrm{kN})$ \\
D & Stress $(\mathrm{MPa})$ \\
E & Extensometer Displacement 1 (mm) \\
F & Extensometer Strain 1 $(\%)$ \\
G & Extensometer Displacement 2 (mm) \\
H & Extensometer Strain 2 (\%) \\
I & Average Extensometer Displacement $(\mathrm{mm})$ \\
J & Average Extensometer Strain $(\mathrm{mm})$ \\
K & Estimated Strain Rate $(\% / m i n)$ \\
L & Corrected Crosshead Strain $(\%)$ \\
\hline
\end{tabular}


The Time value is the number of seconds from the beginning of the test, and has a limited column width in the data files. For the longest tests, the precision of the time column is not adequate to distinguish between successive data points. For this reason, an index is utilized to maintain the order of the data during processing.

Additionally, one or more data files will also transmitted containing summary information for all of the tests (see Table 3). In addition, this information will be inserted into the NDMAS database for download/display.

Table 3. Uniaxial tensile testing summary values.

\begin{tabular}{|ll|}
\hline Col. & \multicolumn{1}{|c|}{ Value } \\
\hline A & Temperature \\
B & Material \\
C & Yield Strength (MPa) \\
D & Ultimate Tensile Strength (MPa) \\
E & Elongation (\%) \\
F & Reduction in Area (\%) \\
\hline
\end{tabular}

The data columns have been categorized according to their disposition in the NDMAS system, as seen in Table 4.

Table 4. Parameters and classification for high temperature materials characterization-uniaxial tension tests.

\begin{tabular}{|c|c|c|c|}
\hline Data Type & Response Variables and Attributes & Data Type & Disposition Category \\
\hline \multirow[t]{2}{*}{ Series Data } & \begin{tabular}{|l} 
Time \\
Stress \\
Strain \\
\end{tabular} & A & Capture \& Display \\
\hline & $\begin{array}{l}\text { Crosshead displacement } \\
\text { Force } \\
\text { Extensometer } 1 \text { displacement } \\
\text { Extensometer } 1 \text { strain } \\
\text { Extensometer } 2 \text { displacement } \\
\text { Extensometer } 2 \text { strain } \\
\text { Average displacement } \\
\text { Average Strain } \\
\text { Estimated Strain Rate } \\
\text { Corrected strain }\end{array}$ & A & Archive \\
\hline Single Values & $\begin{array}{l}\text { Physical properties } \\
\text { Final Specimen Length } \\
\text { Test Temperature } \\
\text { Yield Strength } \\
\text { Ultimate Tensile Strength } \\
\text { Percent Elongation } \\
\text { Percent Reduction in Area }\end{array}$ & A & Capture \& Display \\
\hline Supporting & Photographs & A & Archive \\
\hline
\end{tabular}


The response values required for download/display by the NDMAS system are Time, Stress, and Strain. There are multiple sources for strain in the input data file, and the data used are selected based on the presence of a value using the following column prioritization: Column L, Column J, Column F or H.

Currently, the vault contains uniaxial test data from test series A-1. The data processing methodology for the A-1 test series is discussed in Subsection 3.2.1.

\subsubsection{A-1: Tensile Tests for $S_{m}$ Confirmatory Testing}

Time-independent design allowable stress limits, Sm, are used to indicate the maximum allowable short-duration tensile stresses that can be endured without inducing failure. In support of the determination of time-independent design allowable stresses, Sm, at elevated temperatures for Alloys 617 and $800 \mathrm{H}$, tensile testing was performed in air at multiple temperatures. Ultimate tensile strength, yield strength, reduction of area, and elongation were tabulated for each test. The development of a code case for a new material requires these values at $50^{\circ} \mathrm{C}$ intervals, from room temperature to $50^{\circ} \mathrm{C}$ above the maximum intended use temperature.

All of the data processing is accomplished using SAS Enterprise Guide ${ }^{\circledR}$ software projects. All of the project codes used to process the data are maintained under version control. A summary of the projects used to process the A-1 data is seen in Table 5.

Table 5. Enterprise Guide Projects for processing A-1 data.

\begin{tabular}{|c|c|}
\hline EGP File Name & Purpose \\
\hline 10.ProcessNewDataA1Tensile & $\begin{array}{l}\text { Process the detail data for one data package. Extract the data } \\
\text { from Excel and save as a SAS data set. Push the data into } \\
\text { the Structured Query Language (SQL) vault. Perform } \\
\text { capture testing. }\end{array}$ \\
\hline 20.ProcessSummaryDataA1Tensile & $\begin{array}{l}\text { Process the summary data for a group of experiments. } \\
\text { Extract the data from Excel and save as a SAS data set. Push } \\
\text { the data into the SQL vault. Perform capture testing. }\end{array}$ \\
\hline 30.PullA1DataFromVaultAndPushToDepot & $\begin{array}{l}\text { Pull all available data (detail and summary) from the vault } \\
\text { and push it to SAS data sets in the Depot. }\end{array}$ \\
\hline
\end{tabular}

Each package of data files is first processed using 10.ProcessNewDataA1Tensile.egp. This file pulls the detailed data from the Excel files, converts it to vault format, and pushes the data to the vault. The summary data is processed separately, using 20.ProcessSummaryDataA1Tensile.egp. The detail and summary data are then pulled from the vault and saved in a more usable SAS format in the Depot using the project 30.PullA1DataFromVaultAndPushToDepot.egp.

Manual verification is being performed for the first data package, checking a random sample of values in the vault against the original data set.

The A-1 tensile data is segregated by alloy, and is transferred into the appropriate subdirectory of the folder $\backslash \backslash$ Fserob1 $\backslash$ projects2 $\backslash$ NDMAS $\backslash$ Data_Transfer_To_NDMAS $\backslash A 1$. 


\subsection{Creep-Fatigue Tests}

The creep-fatigue test procedure (Carroll, et al. 2010) applies to both continuous cycle fatigue testing and creep-fatigue testing. Tests A-3, A-20, and A-23 in Table 1are creep-fatigue tests. The applicable ASTM standards are:

- ASTM Standard E 606-04, "Standard Practice for Strain-Controlled Fatigue Testing"

- ASTM Standard E 4-09, "Standard Practice for Force Verification of Testing Machines"

- ASTM Standard E 467-08, "Standard Practice for Verification of Constant Amplitude Dynamic Forces in an Axial Fatigue Testing System"

- ASTM Standard E 83-06, "Standard Practice for Verification and Classification of Extensometer System"

- ASTM Standard E 1012-05, "Standard Practice for Verification of Test Frame and Specimen Alignment"

- ASTM Standard E 2714-09, "Standard Test Method for Creep-Fatigue Testing."

There are three Excel files associated with each experiment. The specimen.xls file contains detailed data for a limited number of stress-strain cycles. The Peak Valley force file contains points of maximum and minimum strain for each cycle. The Peak Valley Strain file contains points of maximum and minimum strain for each cycle, and is for archive purposes only. The sample name is included at the beginning of the file name (e.g., B-3 specimen.xls).

Due to changes in the Creep-Fatigue procedure, there are two different file formats for the data. Originally, the data acquisition system was unable to record temperatures simultaneously with the stress/strain information. For these data sets, Columns B and C in the data files contain Rollover Time and Strain Command, respectively (see Table 6). The temperatures will be submitted in separate files, for archive purposes only.

Table 6. Data columns for original creep-fatigue procedure.

\begin{tabular}{|llll|}
\hline Col. & \multicolumn{1}{c}{ Peak Valley force.xls } & \multicolumn{1}{c|}{ Peak Valley strain.xls } & \multicolumn{1}{c|}{ Specimen.xls } \\
\hline A & Time $(\mathrm{sec})$ & Time $(\mathrm{sec})$ & Time $(\mathrm{sec})$ \\
B & Rollover Time $(\mathrm{sec})$ & Rollover Time $(\mathrm{sec})$ & Rollover Time $(\mathrm{sec})$ \\
C & Strain Command $(\mathrm{mm} / \mathrm{mm})$ & Strain Command $(\mathrm{mm} / \mathrm{mm})$ & Strain Command $(\mathrm{mm} / \mathrm{mm})$ \\
D & Axial Displacement $(\mathrm{mm})$ & Axial Displacement $(\mathrm{mm})$ & Axial Displacement $(\mathrm{mm})$ \\
E & Axial Force $(\mathrm{N})$ & Axial Force $(\mathrm{N})$ & Axial Force $(\mathrm{N})$ \\
F & Axial Strain $(\mathrm{mm} / \mathrm{mm})$ & Axial Strain $(\mathrm{mm} / \mathrm{mm})$ & Axial Strain $(\mathrm{mm} / \mathrm{mm})$ \\
G & Segment & Segment & Segment \\
H & Cycle & Cycle & Corrected Stress $(\mathrm{MPa})$ \\
I & Corrected Stress $(\mathrm{MPa})$ & & \\
J & Stress Ratio & & \\
\hline
\end{tabular}

For the data files resulting from the revised procedure, Columns B and C contain Gage and Shoulder temperatures, respectively. When these values are present, they will be processed and pushed to the vault. 
Table 7. Data columns for revised creep-fatigue procedure.

\begin{tabular}{|llll|}
\hline Col. & \multicolumn{1}{c}{ Valley force.xls } & \multicolumn{1}{c|}{ Valley strain.xls } & \multicolumn{1}{c|}{ Specimen.xls } \\
\hline A & Time $(\mathrm{sec})$ & Time $(\mathrm{sec})$ & Time $(\mathrm{sec})$ \\
B & Gage Temperature $(\mathrm{C})$ & Gage Temperature $(\mathrm{C})$ & Gage Temperature $(\mathrm{C})$ \\
C & Shoulder Temperature $(\mathrm{C})$ & Shoulder Temperature $(\mathrm{C})$ & Shoulder Temperature $(\mathrm{C})$ \\
D & Axial Displacement $(\mathrm{mm})$ & Axial Displacement $(\mathrm{mm})$ & Axial Displacement $(\mathrm{mm})$ \\
E & Axial Force $(\mathrm{N})$ & Axial Force $(\mathrm{N})$ & Axial Force $(\mathrm{N})$ \\
F & Axial Strain $(\mathrm{mm} / \mathrm{mm})$ & Axial Strain $(\mathrm{mm} / \mathrm{mm})$ & Axial Strain $(\mathrm{mm} / \mathrm{mm})$ \\
G & Segment & Segment & Segment \\
H & Cycle & Cycle & Corrected Stress $(\mathrm{MPa})$ \\
I & Corrected Stress $(\mathrm{MPa})$ & & \\
J & Stress Ratio & & \\
\hline
\end{tabular}

The data columns have been categorized according to their disposition in the NDMAS system, as seen in Table 8.

Table 8. Parameters and classification for high temperature materials characterization-creep fatigue tests.

\begin{tabular}{|c|c|c|c|}
\hline Data Type & Response Variables and Attributes & Data Type & $\begin{array}{l}\text { Disposition } \\
\text { Category }\end{array}$ \\
\hline \multirow[t]{3}{*}{ Series Data } & $\begin{array}{l}\text { Time } \\
\text { Axial Count } \\
\text { Corrected Stress } \\
\text { Axial Strain } \\
\text { Thermocouple (more recent files) }\end{array}$ & A & $\begin{array}{l}\text { Capture \& Display } \\
\text { for specific stress- } \\
\text { strain cycles only. } \\
\text { All other cycles are } \\
\text { archived. }\end{array}$ \\
\hline & $\begin{array}{l}\text { Stress } \min / \max \text { at } 2 \text { points per cycle } \\
\text { Stress ratio per cycle }\end{array}$ & A & Capture \& Display \\
\hline & $\begin{array}{l}\text { Axial Displacement } \\
\text { Axial Force } \\
\text { Thermocouple (older files) } \\
\text { Strain min/max at } 2 \text { points per cycle }\end{array}$ & A & Archive \\
\hline \multirow[t]{2}{*}{$\begin{array}{l}\text { Single } \\
\text { Values }\end{array}$} & $\begin{array}{l}\text { Inelastic Strain Range@ Midlife } \\
\text { Stable Load Range } \\
\text { Initial/Stable Stress Max } \\
\text { Cycles for Initial /Stable } \\
\text { Cycles to Initiation } \\
\text { Cycles to Failure }\end{array}$ & A & Capture \& Display \\
\hline & $\begin{array}{l}\text { Physical properties } \\
\text { Diameter at testing temperature }\end{array}$ & A & Archive \\
\hline Supporting & $\begin{array}{l}\text { Photographs } \\
\text { Procedure File }\end{array}$ & A & Archive \\
\hline
\end{tabular}


The time recorded at the beginning of the test is a function of the system, and is irrelevant to the results. Therefore, prior to insertion into the vault, all times are adjusted to indicate time (in seconds) from the beginning of the test. Additionally, the time value has a limited column width in the data files. For tests with higher sampling rates, the precision of the time column is not adequate to distinguish between successive data points. For this reason, an index is utilized to maintain the order of the data during processing.

ASTM Standard 2714 indicates that the logarithmic cycles should be saved: 1, 2, 5, 10, 20, 50, 100, 200, 500, etc. Hence for each logarithmic cycle, the entire stress/strain loop is saved (Time, Segment, Cycle, Strain, Stress, and if available Shoulder and Gage Temperatures). Additionally, for every cycle the maximum and minimum stress values are saved (Time, Segment, Cycle, Stress). Because the stress ratio can be calculated readily from this information, its value is not stored in the vault.

Currently, the vault contains Creep-Fatigue test data from Test Series A-20. The data processing methodology for Test Series A-20 is discussed in Subsection 3.3.1.

\subsubsection{A-20: Creep-fatigue Tests to Support Determination of Creep-Fatigue Interaction Diagram}

These tests were designed to generate creep-fatigue data to support the determination of the creepfatigue interaction diagram in the Alloy 617 Code Case. To quantify the expected improvement in fatigue performance of Alloy 617 in impure helium, tests are planned in both air and the NGNP helium environment. The specimens will be tested in tension at $950^{\circ} \mathrm{C}$. Strain will range from $0.3 \%$ to $1 \%$ with hold times ranging from 0 to 600 minutes. The product form is a plate from a single heat (xyz-CF).

All the A-20 tests are performed on Alloy 617. The A-20 Creep-Fatigue data files are transferred into the network folder $\backslash \backslash$ Fserob1 $\backslash$ projects $2 \backslash N D M A S \backslash$ Data_Transfer_To_NDMAS $\backslash A 20 \backslash$ data.

The codes used to process the A-20 data are summarized in Table 9.

Table 9. Enterprise Guide Projects used to process A-20 data.

\begin{tabular}{|ll|}
\hline \multicolumn{1}{|c|}{ EGP File Name } & \multicolumn{1}{c|}{ Purpose } \\
\hline 10.ProcessNewA20Data & $\begin{array}{l}\text { Process the detail data for one data package. Identify the } \\
\text { stress-strain cycles of interest. Extract the data for the } \\
\text { cycles of interest from Excel and save as a SAS data set. } \\
\text { 20ush the data into the SQL vault. Perform capture testing. } \\
\text { Process the summary data for a group of experiments. } \\
\text { Extract the data from Excel and save as a SAS data set. } \\
\text { Push the data into the SQL vault. Perform capture testing. } \\
\text { 30.PullA20DataFromVaultAndPushToDepot } \\
\end{array} \quad \begin{array}{l}\text { Pull all available data (detail and summary) from the vault } \\
\text { and push it to SAS data sets in the Depot. }\end{array}$ \\
\hline
\end{tabular}

Each package of data files is first processed using 10.ProcessNewA20Data.egp. This file pulls the detailed data from the Excel files, converts it to vault format, and pushes the data to the vault. The summary data is processed separately, using 20.ProcessA20SummaryData.egp. The detail and summary data are then pulled from the vault and saved in a more usable SAS format in the Depot using the project 30.PullA20DataFromVaultAndPushToDepot.egp. 


\subsection{Description of HTM Data Qualification}

Two general types of qualification tests are performed on data loaded into NDMAS:

- Capture tests, which verify that data captured and stored within NDMAS are identical to the source data provided to NDMAS.

- Accuracy tests, which verify the data are an accurate representation of the parameters they are intended to measure.

\subsubsection{Capture Tests}

A capture test is performed when the data is processed to verify that the data captured and stored within the NDMAS SQL database are identical to the source data provided to NDMAS. This test uses a SAS procedure (PROC-COMPARE) to compare the SAS dataset used as input to the SQL database with the SQL database output. Records of these test results are maintained for each HTM data package processed within NDMAS.

A manual verification is used to compare the SQL database output with the original data in the data packages. An independent person checks response variable values in the database against the data in the data packages and documents the results. This manual capture testing is performed for the first data package processed for each type of test series to ensure that the programming for the automatic processing is correct.

\subsubsection{Accuracy Tests}

The accuracy of the HTM data will be verified by the HTM technical staff in ECARs. The process of verifying that all data in the data packages meet specifications is a thorough process with multiple checks to ensure data accuracy. Because this process is so rigorous, no additional accuracy tests are planned for the HTM data. After ECAR approval notification, the NDMAS staff will log an ECAR "accuracy test" as complete in the SQL database for each HTM data package. The data will be considered Qualified after successful completion and documentation (i.e., database logging) of both the NDMAS capture tests and approval of the ECAR.

\subsection{HTM Data QA Documentation}

The NGNP data collection process includes plans describing how data will be collected and the QA activities associated with those data. Review of those plans assures that the work will generate data of appropriate quality for use in the NQA-1 program. Metadata generated by the initial documentation, audits, and acceptance inspection provide the evidence that data meet the requirements of an NQA-1 data collection program. This is documented by the test series within the HTM data stream. Documentation of the QA program implementation in NDMAS is primarily accomplished by references to documents. These include plans, audit reports, nonconformance reports, Engineering Design File (EDFs), and ECARs approved by the VHTR-TDO QA Lead. The documentation data collected by NDMAS will include a reference to a report explicitly listing the data qualification status for each data package.

For the HTM data stream, there are separate test procedures for each type of testing. Currently, test procedures have been developed for tensile tests, creep-fatigue tests, and creep tests.

Tensile tests are governed by the tensile testing procedure (Chapman, et al., 2009) and the extensometer calibration procedure (Lloyd, et al., 2009). Accuracy tests are currently in development for the tensile data. 
Creep-Fatigue tests are governed by the creep-fatigue test procedure (Carroll, et al., 2010) and the extensometer calibration procedure (Lloyd, et al., 2009). Accuracy tests are currently in development for the creep-fatigue data.

Creep tests are governed by the creep test procedure (Lillo, et al., 2010) and the extensometer calibration procedure (Lloyd, et al., 2009). Accuracy tests are currently in development for the creep-data.

Currently, there are no qualified records in the NDMAS vault for the HTM data stream. The detail and summary data from Test Series A-1 have been processed, with the data delivered in two packages. The detail data from the first data package for Test Series A-20 have also been processed. The resulting number of records is seen in Table 10. All data has passed capture testing, and manual verification is in process.

Table 10. Qualification status of the HTM data currently entered in the NDMAS database.

\begin{tabular}{lll}
\multicolumn{1}{c}{ Data Package } & \multicolumn{1}{c}{ Qualified Records } & \multicolumn{1}{c}{ Total Records } \\
\hline HTM A1 Tensile 2010-4-18 & 0 & 1297815 \\
HTM A1 Tensile 2010-5-25 & 0 & 106179 \\
HTM A20 Creep-Fatigue 2010-6-22 & 0 & 918854 \\
Total & 0 & 2322848 \\
\hline
\end{tabular}

\subsection{HTM Data Problems and Resolution}

Minor discrepancies in the data files (e.g., incorrect column names) that were identified during data processing were resolved by conferring with the data producer. Any necessary changes were made to the archived data file within the subversion directory, with log entries to provide documentation. This provides traceability for the modifications, as well as the ability to recover the original data. 


\section{REFERENCES}

ASME, 2000, Quality Assurance Requirements for Nuclear Facility Applications, New York, NY, ASME International, Nuclear Quality Assurance (NQA-1), 2000.

Carroll, L. J. and Wright, R. N., 2010, Creep Fatigue Testing. Idaho National Laboratory, PLN-3346, Rev. 3, May 14, 2010.

Chapman, J. A. and Wright, R. N., 2009, Tensile Testing. Idaho National Laboratory, PLN-3349, Rev. 0, November 4, 2009.

Hull, L. C. and Einerson, J. J., 2010, Very High Temperature Reactor Program Data Management and Analysis Plan, Idaho National Laboratory, PLN-2709, Rev. 2, June 23, 2010.

Lillo, T. M. and Wright, Richard N. 2010. Creep Testing. Idaho National Laboratory, PLN-3386, Rev. 0, January 27, 2010.

Lloyd, W. R. and Wright, R. N.. 2009. Extensometer Calibration Procedure, Idaho National Laboratory. PLN-3347. Rev. 0, November 4, 2009.

Roberts, G. D. and Trost, A L., 2009, Very High Temperature Gas Reactor Technology Development Office Quality Assurance Program Plan, Idaho National Laboratory, PLN-2690, Rev. 3, December 9 , 2009.

Wright, R. N., 2008, Next Generation Nuclear Plant Intermediate Heat Exchanger Materials Research and Development Plan, Idaho National Laboratory, PLN-2804, Rev. 0, April 30, 2008. 